This item was submitted to Loughborough's Research Repository by the author.

Items in Figshare are protected by copyright, with all rights reserved, unless otherwise indicated.

\title{
Psychosocial factors associated with physical activity in ambulatory and manual wheelchair users with spinal cord injury: a mixed-methods study
}

\section{PLEASE CITE THE PUBLISHED VERSION}

http://dx.doi.org/10.3109/09638288.2015.1045991

\section{PUBLISHER}

(C) Taylor \& Francis

\section{VERSION}

AM (Accepted Manuscript)

\section{PUBLISHER STATEMENT}

This work is made available according to the conditions of the Creative Commons Attribution-NonCommercialNoDerivatives 4.0 International (CC BY-NC-ND 4.0) licence. Full details of this licence are available at: https://creativecommons.org/licenses/by-nc-nd/4.0/

\section{LICENCE}

CC BY-NC-ND 4.0

\section{REPOSITORY RECORD}

Ginis, Kathleen A. Martin, Anthony Papathomas, Marie-Josee Perrier, Brett M. Smith, and Shape-Sci Research Group. 2019. "Psychosocial Factors Associated with Physical Activity in Ambulatory and Manual Wheelchair Users with Spinal Cord Injury: A Mixed-methods Study". figshare. https://hdl.handle.net/2134/21043. 


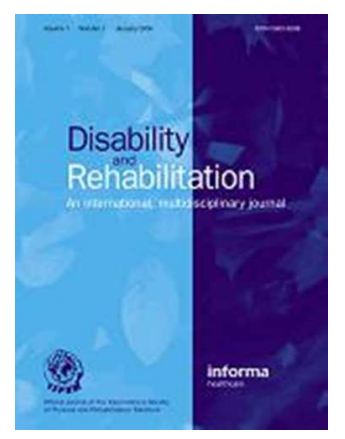

\section{Psychosocial factors associated with physical activity in ambulatory and manual wheelchair users with spinal cord injury: A mixed-methods study}

\begin{tabular}{|r|l|}
\hline Journal: & Disability and Rehabilitation \\
\hline Manuscript ID: & TIDS-10-2014-007.R1 \\
\hline Manuscript Type: & Research Paper \\
\hline Keywords: & incomplete spinal cord injury, exercise, mixed-methods, sport, self-efficacy \\
\hline \multicolumn{2}{|}{} \\
\hline
\end{tabular}

SCHOLARONE ${ }^{\text {Im }}$

Manuscripts 


\section{IMPLICATIONS FOR REHABILITATION}

- Rehabilitation practitioners must be sensitive to the unique needs of spinal cord injured individuals who are ambulatory, and tailor physical activity promotional strategies to suit the needs of this distinct group.

- Lack of wheelchair skills is a participation barrier for ambulators; ambulators should be introduced to activities that do not require wheelchair use, such as swimming, hand-cycling and adapted forms of circuit training.

- Strategies that encourage wheelchair skill development in non-wheelchair using ambulators, may increase physical activity opportunities for this segment of the spinal injured population. 
Psychosocial factors associated with physical activity in ambulatory and manual wheelchair users with spinal cord injury: A mixed-methods study

Kathleen A. Martin Ginis ${ }^{1}$, Anthony Papathomas ${ }^{2}$, Marie-Josée Perrier ${ }^{1}$, Brett Smith $^{2}$ and the SHAPE-SCI Research Group

${ }^{1}$ McMaster University, Department of Kinesiology, Hamilton ON, Canada

${ }^{2}$ Loughborough University, School of Sport, Exercise and Health Sciences, Leicestershire, UK.

KEYWORDS: incomplete spinal cord injury, physical activity, exercise, mixed-methods 


\begin{abstract}
Purpose: To identify psychosocial factors which explain lower levels of leisure time physical activity (LTPA) in persons with spinal cord injury (SCI) who are ambulatory relative to those who use manual wheelchairs.

Method: For the quantitative study component, 347 adults with SCI (78\% male; $M$ age $=47.7$ ) completed baseline measures of LTPA attitudes, subjective norms, perceived behavioural control, and intentions. Six months later, LTPA was assessed. The qualitative component involved semi-structured interviews with 6 ambulant adults with SCI (5 male, $M$ age $=52.8$ ) addressing LTPA experiences with an emphasis on barriers and facilitators.
\end{abstract}

Results: Ambulatory individuals had poorer attitudes towards LTPA than chair users $(p=.004)$. Their attitudes had significant indirect effects on LTPA, through intentions. Perceived behavioural control was a significant negative predictor of LTPA. Qualitative analysis revealed three themes: an underestimated disability; low wheelchair skill efficacy; and experiencing chronic pain.

Conclusions: Poorer attitudes toward LTPA may partially explain why ambulatory individuals are less active. The qualitative and quantitative data suggest ambulators are an often-overlooked subgroup in need of targeted resources to enhance their attitudes, wheelchair skill self-efficacy and awareness of LTPA opportunities. 
Only $50 \%$ of adults living with spinal cord injury (SCI) participate in leisure time physical activity (LTPA) such as exercise, sport, or active play [1]. Of these individuals, only a fraction are meeting evidence-based physical activity recommendations for people with SCI [2]. There are profound physical and psychological health risks associated with physical inactivity and abundant health benefits associated with an active lifestyle $[3,4,5,6]$. As such, there is tremendous value in identifying factors that might influence physical activity participation in the SCI population.

One such factor is mode of mobility. A study of nearly 700 adults with SCI revealed that those who used a manual wheelchair as their primary mode of mobility outside of the home, reported significantly more min/day of LTPA than those who used a power wheelchair or ambulated with a gait aid [1]. Given differences in physical functioning and impairment between those who can self-propel a wheelchair versus those who cannot, higher levels of LTPA in manual versus power wheelchair users was expected. It was somewhat surprising, however, that ambulatory individuals reported nearly $50 \%$ fewer min/day of LTPA than manual wheelchair users, as those who are ambulatory might be expected to be more active by virtue of their higher level of functioning.

A possible explanation for these unexpected findings is that ambulatory men and women with SCI face unique psychosocial barriers to LTPA. For instance, compared to wheelchair-reliant individuals with SCI, those who ambulate report greater fatigue, pain, and pain interference in their daily lives [7]. These symptoms could undermine ambulators' sense of perceived control over their ability to be physically active on a 
routine basis [8]. Furthermore, because walking with canes, crutches and orthoses is more metabolically demanding than self-propelling a wheelchair $[9,10]$, ambulators may have particularly negative attitudes toward LTPA, stemming from beliefs that ambulatory forms of LTPA (e.g., going for a walk) are excessively effortful and exhausting [9].

We are unaware of any published studies that have exclusively addressed psychosocial aspects of LTPA participation in ambulatory individuals with SCI. Thus, the purpose of the present study was to examine psychosocial factors that could account for the lower levels of LTPA reported among ambulators relative to manual wheelchairusers [1]. Identification of such factors is vital for developing LTPA-enhancing strategies that are sensitive to the needs of different segments of the SCI population, including those who use different mobility assistive devices.

The first part of our study employed Ajzen's [11] Theory of Planned Behavior as a conceptual framework. This theory has been used extensively to understand and predict LTPA in a wide range of populations [12] including those with SCI [13,14]. According to the theory's tenets, intentions to perform a behaviour are the most proximal predictor of that behaviour. Intentions are influenced by attitudes, social pressure (i.e., subjective norms) and perceived control over the behaviour. Perceived behavioural control is also hypothesized to have a direct influence on behaviour (see Figure 1). We predicted that in our study, ambulators would score lower than manual chair users on measures of attitudes, perceived behavioural control, subjective norms, and intentions to engage in LTPA. In addition, using a prospective study design, path analyses were undertaken as an 
exploratory step to test a model of the Theory of Planned Behaviour variables for predicting LTPA in ambulators and wheelchair users.

Given the lack of research addressing ambulant SCI individuals' LTPA motivations, exploring this population through qualitative interviews was deemed a necessary addition to the study. A qualitative approach, working in conjunction with quantitative data, enabled a more complex and richly layered examination [15] of the contrarian finding that ambulant individuals engage in less LTPA than those with lower functioning. Qualitative research has been described as "discovery-oriented" for its capacity to illuminate an unusual phenomenon when alternative explanations are inadequate or totally lacking [16]. Accordingly, in-depth, open-ended interviews were conducted with a small group of ambulators. An emphasis on personal perspectives instead of predetermined theory, allowed for previously unconsidered issues to emerge.

\section{Methods}

\section{Participants}

The first part of the study involved a secondary analysis of a subset of data collected in the Study of Health and Activity in People with Spinal Cord Injury (SHAPESCI; [17]). The subset was restricted to the 347 participants (78\% male; $M$ age $=47.7$ years $\pm 13.0 ; M$ years post injury $=16.1 \pm 11.0$ ) who (a) reported their primary mode of mobility outside of the home was a manual chair (82\%), or a gait aid (18\%), and (b) completed both baseline and 6-month assessments in the SHAPE-SCI protocol. The proportion of gait aid users was comparable to the proportion of individuals in the 2013 U.S. Spinal Cord Injury Model Systems database who were able to walk for 1 street 
block at 15 years post-injury $(19.3 \%$; [18]). Characteristics of the two sub-groups are presented in Table 1.

The qualitative component of the study utilized a purposive sampling strategy, whereby participants are selected based on having specific experience of the topic under investigation (i.e. being ambulant with spinal cord injury). Following university ethics board approval, 6 ambulant spinal cord injured individuals $(5$ male; $\mathrm{M}$ age $=52.8$ years \pm 13.0; $\mathrm{M}$ years post injury $=15.3 \pm 25$ ) were recruited for interview.

\section{Measures and Protocol}

\section{Questionnaires}

The complete SHAPE-SCI data collection protocol is reported elsewhere [17]. For the purpose of the present study, only measures of the Theory of Planned Behavior constructs (collected at baseline) and LTPA (collected 6 months later) were analyzed. All measures were administered during a telephone interview.

Measures of the theoretical constructs were drawn from previous work involving adults with SCI [13] and assessed respondents' thoughts and feelings toward performing moderate to heavy intensity LTPA for at least $30 \mathrm{~min}$, on most days of the week, over the next 6 months. Direct measures were used to assess attitudes (affective and instrumental attitudes; six items), subjective norms (injunctive norm; two items), perceived behavioral control (perceived control and self-efficacy; five items), and intentions (two items). All items were rated on 7-point Likert-type scales, with higher scores indicating more 
positive thoughts and feelings. An overall score for each construct was computed by averaging the item scores for that construct.

LTPA was assessed using the Physical Activity Recall Assessment for People with SCI (PARA-SCI; [19]). The PARA-SCI has demonstrated good construct validity and reliability as a measure of physical activity among people with SCI [20,21,19]. As per the PARA-SCI protocol, during a structured interview, participants recalled all physical activities they performed over the previous 3 days that required physical exertion. Participants then rated the intensity of each activity as mild, moderate, heavy or "nothing at all" using standardized definitions developed specifically for people with SCI [19]. The interviewer classified each activity as LTPA or an activity of daily living. Because the Theory of Planned Behavior measures asked specifically about moderate to heavy intensity LTPA, the average number of min/day of moderate + heavy intensity LTPA was calculated and served as the measure of LTPA.

\section{Interviews}

For the qualitative side of this project, semi-structured interviews were used to elicit life-story data pertaining to participants' personal perspectives on LTPA. Semistructured interviews allowed participants the freedom to discuss issues that they perceived as most relevant to their own experience [22]. This participant-led approach facilitates unique and unforeseen insights that fall outside of a researcher's pre-prescribed hypotheses and questionnaire-driven questions [23]. At the same time, the presence of a loose structure enables the interviewer to ensure that certain broad areas of conceptual interest are addressed. For example, questions were broadly framed around perceived 
barriers and facilitators to LTPA. Open questions - such as what makes LTPA

difficult/easier for you? - encouraged participants to deliver extended responses, thereby generating rich data. When rich data were not forthcoming, a series of probes - that is, curiosity-driven questions - were called upon to prompt further detail (e.g. can you tell me more about that? How did that make you feel?).

Interviews were conducted face-to-face, in a location convenient to the participant. Face-to-face interviews have been shown to be effective at engendering trust and rapport between researcher and participant, thereby encouraging the sharing of sensitive thoughts and feelings [23]. Relationship quality is an important determinant of interview success when questions ask participants to elaborate on personal experiences. Interviews lasted between 88 and 133 minutes, with each digitally recorded and transcribed verbatim. Over 10 hours of interview data were subject to a thematic analysis.

\section{Analyses}

Quantitative Analyses. Using SPSS v. 22, a series of one-way ANCOVAs tested for between-groups differences in the Theory of Planned Behaviour measures. All comparisons met assumptions of ANCOVA [24]. Initially, these analyses controlled for between-groups differences in age and years post-injury. As age was not a significant covariate in any analysis, it was subsequently removed.

Next, theoretical relationships between the Theory of Planned Behaviour constructs and LTPA were modeled through path analysis. Using AMOS v. 18, separate models were computed for ambulators and wheelchair users. All paths were estimated 
using maximum likelihood estimation and met the requirements for identification [25]. Model fit was assessed using Chi-square, Comparative Fit Index (CFI), Normed Fit Index (NFI), and the Root Mean Square Error of Approximation (RMSEA). Non-significant Chi-square values, CFI and NFI values above .95, and RMSEA values under .08 indicate models with good fit $[25,26]$. Prior to computing the models, five manual wheelchairusers and two ambulators were identified as statistical outliers with LTPA values $>3$ SDs from the mean; their LTPA values were recoded as the next lowest LTPA value in their group [24].

Qualitative Analysis. Thematic analysis was used to make sense of the interview data. It enables a researcher to organize interview data into conceptual themes that are reflective of a given group's experiences [23]. Although numerous variations of thematic analysis exist, our approach was based on the flexible techniques outlined by Braun and Clark [27] for use in psychology research. First, data immersion involved repeated reading of each transcript while making loose annotations. Second, with increased familiarity with the data, loose annotations became more concrete conceptual codes. Third, individual codes were grouped according to common meaning in order to form overarching themes. Fourth, themes were reviewed for their fidelity to the initial codes, the full transcripts and the original audio files. Here, it was useful to ask the question: do these constructed themes give a good sense of the original interviews? In addition, the conceptual content of themes was scrutinized to ensure that each was sufficiently different to the other. Fifth, with themes organized, each was attributed a descriptive title that defined its conceptual contribution. Sixth, in line with the permeability of the previous steps, analysis continues up to the writing of the actual report. In principle, if 
PHYSICAL ACTIVITY AND SCI 10

new analytical connections and insights surface during the writing stage, previous steps can be altered accordingly.

\section{Results}

Quantitative results are presented first, followed by the qualitative findings. Presenting contrasting methodological approaches within a single results section is an accepted convention in mixed methods research [15].

\section{Quantitative results}

Results of the ANCOVAs are presented in Table 2. At baseline, ambulators had poorer attitudes towards LTPA than manual chair users $(p=.004)$. No other differences were significant.

Figure 1 shows the results for tests of direct effects. The indirect effects are reported in text. Among ambulators, perceived behavioural control was directly, albeit negatively related to LTPA $(\beta=-.26, \mathrm{p}<.05)$ suggesting ambulators with the greatest sense of control over LTPA participated in the least activity. Only attitudes had a significant indirect relationship with LTPA, through intentions $(\beta=.21, \mathrm{p}<.05)$. The model accounted for $39 \%$ and $13 \%$ of the variance in intentions and LTPA, respectively and was an excellent fit to the data $\left(x^{2}[2 \mathrm{df}]=1.716, \mathrm{p}>.05 ; \mathrm{CFI}=1.00 ; \mathrm{NFI}=.976 ; \mathrm{RMSEA}\right.$ $=.000)$. Among manual chair users, perceived behavioural control was not directly associated with LTPA. However, attitudes $(\beta=.12, \mathrm{p}<.01)$, subjective norms $(\beta=.043$, $\mathrm{p}<.05)$, and perceived behavioural control $(\beta=.049, \mathrm{p}<.01)$ were significant indirect predictors of LTPA through intentions. The model accounted for $44 \%$ of the variance in 


\author{
intentions and $8 \%$ of the variance in LTPA and was an excellent fit to the data $\left(\mathrm{x}^{2}[2 \mathrm{df}]\right.$ \\ $=1.563, \mathrm{p}>.05 ; \mathrm{CFI}=1.00 ; \mathrm{NFI}=.996 ; \mathrm{RMSEA}=.000)$.
}

\title{
Qualitative results
}

Three broad themes emerged: (1) an underestimated disability (2) low wheelchair skill efficacy, and (3) experiencing chronic pain. Drawing on participants' quotes (pseudonyms used), each of these themes is illustrated below.

\begin{abstract}
An underestimated disability
Ambulators expressed frustration that their SCI was often misconceived by others, including fellow spinal injured people and some health professionals, as less serious than the injuries sustained by fulltime wheelchair users:
\end{abstract}

There does seem to be this gap between people in wheelchairs and people who've fully recovered and this bit in the middle...sometimes you think 'does anyone know what's going on or understand this?' We're walking but to say we're the lucky ones is wrong. In some sense, if you look at it philosophically, you can say we're the unlucky ones because we have a lot of the same issues as other people have which are completely unrecognized.

Oliver (T5, incomplete) is quick to quash the notion of ambulators as "lucky" relative to fulltime chair users. There is an overt tension between the visible disability experienced by chair users and the, at times, invisible disability experienced by ambulators. If ambulators are considered "less disabled" than chair users, or not seen as disabled at all, 
they are less likely to be targeted with LTPA support and guidance. Further, Oliver hints at a lack of group identity for ambulators who, for him, are lost in a gap between people using wheelchairs and those who have fully recovered. Clearly defined groups have been shown to facilitate effective physical activity promotion efforts [28].

\title{
Low wheelchair skill-efficacy
}

Participants also felt that their lack of wheelchair use in everyday life impeded their LTPA opportunities. This issue was articulated by Eva (T6, incomplete):

\author{
I'm an in-betweener, I'm not a full time wheelchair user. So I'm rubbish in my \\ wheelchair and wheelchair skills are really important. I thought about wheelchair \\ basketball but I just thought, well, I'm not going to be able to manage it
}

\begin{abstract}
The perceived lack of appropriate wheelchair skills was considered a barrier because it reduced the LTPA options available. If opportunities for LTPA, particularly sporting opportunities, are primarily geared towards wheelchair users, gait-aided spinal injured individuals may feel excluded.
\end{abstract}

\section{Experiencing chronic pain}

The experience of chronic pain was considered both a facilitator and a barrier to LTPA. As a facilitator, participants were motivated by pain-relief benefits from physical activity. As a barrier, LTPA could aggravate feelings of pain: 
PHYSICAL ACTIVITY AND SCI 13

I think there's always, anything I talk about in reference to spinal injury or activity there has to be reference to the pain, because that's been a constant factor and it's never been something that I've been able to totally control

\begin{abstract}
As described above by Tom (L1, incomplete), an inability to properly manage ongoing pain detracted from his efforts to be regularly active. Although pain as a barrier to LTPA is likely to be equally relevant to wheelchair users, it may be accentuated in the ambulant population due to the pain aggravation and fatigue accumulation associated with walking and standing [7].
\end{abstract}

\title{
Discussion
}

This study utilized a mixed-methods approach to examine psychosocial factors that could account for lower levels of LTPA among ambulatory individuals relative to manual wheelchair users with SCI. In partial support of our hypotheses, quantitative analyses revealed ambulatory individuals held more negative attitudes toward LTPA than manual wheelchair users. No other between-groups differences were significant. Moreover, attitudes, through their effects on intentions, were the only psychosocial variable to positively predict LTPA. Interviews with ambulators provided explanatory insight regarding these findings, with key themes emerging around others' underestimation of their disability, low wheelchair self-efficacy, and the experience of chronic pain.

Questionnaire items captured both the instrumental and affective dimensions of attitudes [29]. Thus, the quantitative analyses indicated that, compared to wheelchair users, ambulators consider LTPA to have fewer benefits and to be less pleasant. The 
qualitative data revealed that poorer attitudes might reflect a lack of knowledge about the benefits of LTPA, as well as a lack of perceived opportunity to engage in pleasant forms of LTPA. Specifically, many people with an incomplete SCI may be unaware of, or unconvinced of, the pain-relief benefits associated with an active lifestyle [30]. Poor affective attitudes may be born out of apathy for the chronic pain often experienced by those with an incomplete SCI [7] and a fear that daily pain could be exacerbated by physical activity. Furthermore, given pain is often interlinked with fatigue [31], and with ambulant day-to-day living considered more energy-intensive than wheelchair-based living [9,10], LTPA may be perceived as both burdensome and unnecessary.

Given that attitudes were shown to have an indirect effect on LTPA (through intentions), our quantitative and qualitative findings highlight the need for attitudeenhancing interventions for ambulators that focus on the benefits of LTPA and, perhaps more importantly, identify fun, pain-free activities that are appropriate for this population. Such information is vital for enhancing motivation (i.e., intentions) to be active. Our interview participants felt part of a subgroup that was poorly understood, and that their needs and their disability were underestimated. These sentiments suggest that ambulators are being overlooked in terms of the provision of physical activity-enhancing materials, strategies, and services. For instance, existing LTPA resources for persons with SCI may lack images of ambulators, or information on LTPA benefits specific to those who ambulate (cf. [32]). Such resources need to do a better job of targeting this segment of the SCI population. In so doing, health promotion efforts may need to call upon more innovative practices. For example, creating empirically grounded motivational stories may help connect personally and emotionally with a group that consider themselves to be 
very much alienated [33]. Given some evidence of demographic shifts over the past 20 years toward greater proportions of individuals with incomplete SCI [34] and, presumably, greater numbers of ambulators, practitioners need to be prepared to meet growing demands for targeted resources for this sub-population.

A unique contribution of the qualitative study component was the finding that ambulators considered wheelchair sports inaccessible due to a perceived lack of wheelchair skills. To address this participation barrier, activity promoters could target ambulators by offering activity programs that do not require wheelchair use, such as swimming, hand-cycling, and adapted forms of circuit training. Alternatively, ambulators could receive wheelchair skills training to boost their self-efficacy [35] which, in turn, could increase their likelihood of participating in wheelchair-based LTPA [36].

The negative relationship between perceived behavioural control and LTPA among ambulators was unexpected. Previous research has found perceived behavioural control is not a significant direct predictor of LTPA in people with SCI [13]--a finding consistent with our results for manual chair users. The observed negative association might indicate that ambulators are overly confident in their sense of control over LTPA; consequently, they may become frustrated when they encounter barriers to LTPA and abandon their efforts altogether. As a remedy, teaching people with SCI to identify and develop plans to cope with barriers, should they arise, is an effective strategy for enhancing LTPA participation [37]. Another possibility is that ambulators are simply unable to act on their motivation and perceptions of control, because they lack ample 
opportunities to be active. This explanation is supported by the interview data, and participants' comments regarding the lack of LTPA options, support, and guidance.

\section{Limitations and Conclusion}

First, we acknowledge that the Theory of Planned Behaviour explained relatively little variance in LTPA behaviour. These results echo previously expressed concerns regarding the theory's predictive capabilities [38], and also reflect the instability of LTPA participation in the SCI population [39], particularly over a 6-month period. On a related note, with a larger sample of ambulators, some of the nonsignificant pathways may have been significant. We also acknowledge the limitations of using a self-report measure of LTPA; however, we retain confidence in our findings given that the PARA-SCI is superior to the other widely available measures of energy expenditure in persons with SCI (other questionnaire, heart rate monitoring, arm-band accelerometer) when referenced against the gold-standard of doubly labeled water [20]. Finally, the interview participants were all middle-aged or older and had some experience, past or present, with LTPA. The perspectives of younger individuals and those completely inactive, may provide additional important insights into why ambulators are often less active than their wheelchair-using counterparts.

Despite these limitations, our mixed-methods approach has provided new insights to explain the disproportionate levels of physical activity among ambulators versus manual wheelchair users with SCI. Our quantitative and qualitative findings suggest that ambulators are an often-overlooked group, in need of targeted informational resources and programs, to enhance their attitudes, self-efficacy for wheelchair skills, and 
awareness of opportunities for physical activity. Until these issues are addressed, ambulators will continue to be less active than manual wheelchair users and fall short in attaining the numerous health-related benefits of an active lifestyle.

Declaration of Interest

The Study of Health and Activity in People with SCI (SHAPE-SCI) was funded by an Operating Grant from the Canadian Institutes of Health Research. The qualitative portion of the study was supported by funding from the Coca-Cola Foundation. Preparation of the manuscript was supported by a Postdoctoral Fellowship from the Social Sciences and Humanities Research Council of Canada, awarded to M. J. Perrier. The authors report no other declarations of interest. 
References

1. Martin Ginis KA, Latimer AE, Arbour-Nicitopoulos KP, Buchholz AC, Bray SR, Craven BC, Hayes KC, Hicks AL, McColl MA, Potter PJ and others. Leisure time physical activity in a population-based sample of people with spinal cord injury Part I: Demographic and injury-related correlates. Archives of Physical Medicine and Rehabilitation 2010;91(5):722-728.

2. Martin Ginis KA, Hicks AL, Latimer AE, Warburton DER, Bourne C, Ditor DS, Goodwin DL, Hayes KC, McCartney N, McIlraith A and others. The development of evidence-informed physical activity guidelines for adults with spinal cord injury. Spinal Cord 2011;49:1088-1096.

3. Martin Ginis KA, Jetha A, Mack DE, Hetz S. Physical activity and subjective well-being among people with spinal cord injury: A meta-analysis. Spinal Cord 2010;48:65-72.

4. Hicks AL, Martin Ginis KA, Pelletier CA, Ditor DS, Foulon B, Wolfe DL. The effects of exercise training on physical capacity, strength, body composition and functional performance among adults with spinal cord injury: A systematic review. Spinal Cord 2011;49(11):1103-1127.

5. Nooijen CFJ, de Groot S, Postma K, Bergen MP, Stam HJ, Bussmann JBJ, van den Berg-Emons R. A more active lifestyle in persons with a recent spinal cord injury benefits physical fitness and health. Spinal Cord 2012;50:320-323.

6. van der Scheer JW, de Groot S, Tepper M, Gobets D, Veeger D, van der Woude L. Wheelchair-specific fitness of inactive people with long-term spinal cord injury. Journal of Rehabilitation Medicine 2015;Jan 16.

7. Saunders LL, Krause JS, DiPiro ND, Kraft S, Brotherton S. Ambulation and complications related to assistive devices after spinal cord injury. Journal of Spinal Cord Medicine 2013;36(6):652-659.

8. Stapleton J, Martin Ginis KA, The SHAPE-SCI Research Group. Sex differences in theory-based predictors of leisure time physical activity in a populationbased sample of adults with spinal cord injury. Physical Medicine and Rehabilitation 2014;doi: 10.1016/j.apmr.2014.03.021.

9. Merati G, Sarchi P, Ferrarin M, Pedotti A, Veicsteinas A. Paraplegic adaptation to assisted-walking: energy expenditure during wheelchair versus orthosis use. Spinal Cord 2000;38(1):37-44.

10. Bateni H, Maki B. Assistive devices for balance and mobility: Benefits, demands, and adverse consequences. Archives of Physical Medicine and Rehabilitation 2005;86:134-145.

11. Ajzen I. From intentions to action a theory of planned behavior. In: Kuhl J, Beckmann J, editors. Action Control: From Cognition to Behavior. Heildelberg: Springer-Verlag; 1985. p 11-39.

12. Hagger MS, Chatzisarantis NLD, Biddle SJH. A meta-analytic review of the theories of reasoned action and planned behavior in physical activity: Predictive validity and the contribution of additional variables. Journal of Sport and Exercise Psychology 2002;24 3-32. 
13. Latimer AE, Martin Ginis KA. The theory of planned behavior in prediction of leisure time physical activity among individuals with spinal cord injury. Rehabilitation Psychology 2005;50(4):389-396.

14. Ellis R, Kosma M, Cardinal BJ, Bauer JJ, McCubbin J. Physical activity beliefs and behaviour of adults with physical disabilities. Disability and Rehabilitation 2007;29(15):1221-1227.

15. Smith B, Sparkes AC, Phoenix C, Kirkby J. Qualitative research in physical therapy: A critical discussion on mixed-methods research. Physical Therapy Review 2012;17(6):374-381.

16. Rennie DL. Qualitative research as methodical hermeneutics. Psychological Methods 2012;17(3):385.

17. Martin Ginis KA, Latimer AE, Buchholz AC, Bray SR, Craven BC, Hayes KC, Hicks AL, McColl MA, Potter PJ, Smith K and others. Establishing evidencebased physical activity guidelines: Methods for the Study of Health and Activity in People with Spinal Cord Injury (SHAPE SCI). Spinal Cord 2008;46(3):216-221.

18. National Spinal Cord Injury Statistical Center. Spinal Cord Injury Model Systems: 2013 Annual Report Complete Public Version. Birmingham, Alabama2013.

19. Martin Ginis KA, Latimer AE, Craven BC, Hicks AL. Development and preliminary evaluation of an activity measure for people with spinal cord injury. Medicine and Science in Sports and Exercise 2005;37:1099-1111.

20. Tanhoffer RA, Tanhoffer AI, Raymond J, Hills AP, Davis GM. Comparison of methods to assess energy expenditure and physical activity in people with spinal cord injury. Journal of Spinal Cord Medicine 2012;35(1):35-45.

21. Latimer AE, Martin Ginis KA, Craven BC, Hicks AL. The Physical Activity Recall Assessment for people with spinal cord injury: Validity. Medicine and Science in Sports and Exercise 2006;38(2):208-216.

22. Hugh-Jones $S$. The interview in qualitative research. In: Forrester MA, editor. Doing qualitative research in psychology: A practical guide London: Sage; 2010. p 77-97.

23. Sparkes AC, Smith B. Qualitative research methods in sport, exercise and health: From process to product. London: Routledge; 2014.

24. Tabachnick BG, Fidell LS. Using Multivariate Statistics. Boston, MA: Allyn and Bacon; 2007.

25. Kline RB. Principles and practice of structural equation modeling. New York: The Guilford Press; 2005.

26. $\mathrm{Hu} \mathrm{L}$, Bentler PM. Cutoff criteria for fit indexes in covariance structure analysis: Conventional criteria versus new alternatives. Structural Equation Modeling 1999;6(1-55).

27. Braun V, Clarke V. Using thematic analysis in psychology. Qualitative Research in Psychology 2006;3(2):77-101.

28. Heath GW, Parra DC, Sarmiento OL, Andersen LB, Owen N, Goenka S, Montes F, Brownson RC. Evidence-based intervention in physical activity: lessons from around the world. The Lancet 2012;380(9838):272-281. 
29. Ajzen I. 2002 Construction of a standard questionnaire for the theory of planned behavior.

<http://people.umass.edu/aizen/pdf/tpb.measurement.pdf\%3E.

30. Martin Ginis KA, Latimer AE, McKecknie K, Ditor DS, McCartney N, Hicks AL, Craven C, Bugaresti J. Using exercise to enhance subjective well-being among people with spinal cord injury: The mediating influences of stress and pain. Rehabilitation Psychology 2003;48:157-164.

31. Wollaars MM, Post M, van Asbeck FW, Brand N. Spinal cord injury pain: the influence of psychologic factors and impact on quality of life. The Clinical Journal of Pain 2007;23(5):383-391.

32. Arbour-Nicitopoulos KP, Martin Ginis KA, Latimer-Cheung AE, Bourne C, Campbell D, Cappe S, Ginis S, Hicks AL, Pomerleau P, Smith K. Development of an evidence-informed physical activity resource for adults with spinal cord injury: The SCI Get Fit Toolkit. Spinal Cord 2013;51(6):491-500.

33. Smith B, Papathomas A, Martin Ginis KA, Latimer-Cheung AE. Understanding physical activity in spinal cord injury rehabilitation: translating and communicating research through stories. Disability and Rehabilitation 2013;35(24):2046-2055.

34. Nijendijk JHB, Post MWM, van Asbeck FWA. Epidemiology of traumatic spinalc cord injuries in the Netherlands in 2010. Spinal Cord 2014;52:258263.

35. Sakakibara BM, Miller WC, Souza M, Nikolova V, Best KL. Wheelchair skills training to improve confidence with using a manual wheelchair among older adults: A pilot study. Archives of Physical Medicine and Rehabilitation 2013;94(6):1031-1037.

36. Phang SH, Martin Ginis KA, Lemay V, Routhier F. The role of self-efficacy in the wheelchair skills-physical activity relationship among manual wheelchair users with spinal cord injury. Disability and Rehabilitation 2012;34:625-632.

37. Arbour-Nicitopoulos KP, Martin Ginis KA, Latimer AE. Planning, leisure-time physical activity, and coping self-efficacy in persons with spinal cord injury: A randomized controlled trial. Archives of Physical Medicine and Rehabilitation 2009;90(12):2003-2011.

38. Sniehotta FF, Presseau J, Araújo-Soaresa V. Time to retire the theory of planned behaviour. Health Psychology Review 2014;8(1):1-7.

39. van den Berg-Emons RJ, Bussmann JB, Haisma JA, Sluis TA, van der Woude LH, Bergen MP, Stam HJ. A prospective study on physical activity levels after spinal cord injury during inpatient rehabilitation and the year after discharge. Archives of Physical Medicine and Rehabilitation 2008;89(11):2094-2101. 
Table 1. Characteristics of Study Participants

\begin{tabular}{lcc}
\hline & $\begin{array}{c}\text { Ambulators } \\
(\mathrm{n}=63)\end{array}$ & $\begin{array}{c}\text { Manual Wheelchair } \\
\text { Users } \\
(\mathrm{n}=284)\end{array}$ \\
\hline Sex & $76 \%$ & $78 \%$ \\
$\quad$ Male & $24 \%$ & $22 \%$ \\
$\quad$ Female & $53.7 \pm 2.0$ & $46.4 \pm 0.7$ \\
Age (years) & & $17.0 \pm 0.6$ \\
Years post-injury* & $11.8 \pm 1.5$ & \\
& & $38 \%$ \\
Injury Level & & $60 \%$ \\
$\quad$ C1-C8 (Tetraplegic) & $52 \%$ & \\
T1-S5 (Paraplegic) & $43 \%$ & $14.3 \pm 1.5$ \\
& & \\
Min/day of moderate-heavy LTPA & & \\
& $9.2 \pm 3.2$ & \\
& &
\end{tabular}

Note. Continuous variables are expressed as means and standard errors.

*t-tests indicated significant differences between ambulators and wheelchair users, $p \mathrm{~s}$ $=.001$.

${ }^{+}$Because some participants did not know their injury level or declined to respond, values do not total to $100 \% \cdot \mathrm{x}^{2}$ tests indicated no significant differences in the proportion of tetraplegics or paraplegics who were ambulators versus manual wheelchair users ( $p \mathrm{~s}$ $>.09)$.

${ }^{\circ}$ LTPA values are estimated marginal means that control for age and number of years post-injury. Given the unequal variances and sample sizes and the large deviations of the data from normality, a between-groups analysis could not be computed. 
Table 2. Means and Standard Errors for Measures of the Theory of Planned Behaviour Constructs for Ambulators and Manual Wheelchair Users with a Spinal Cord Injury

\begin{tabular}{|c|c|c|c|c|}
\hline Mode of Mobility & $\begin{array}{l}\text { Attitudes } \\
\text { M (SE) }\end{array}$ & $\begin{array}{l}\text { Subjective } \\
\text { Norms } \\
\text { M (SE) }\end{array}$ & $\begin{array}{l}\text { Perceived } \\
\text { Behavioural } \\
\text { Control } \\
\mathrm{M}(\mathrm{SE})\end{array}$ & Intentions \\
\hline Ambulate with Gait Aid & $5.20 *$ & 5.67 & 5.50 & 4.90 \\
\hline$(n=63)$ & $(.14)$ & $(.18)$ & $(.17)$ & $(.24)$ \\
\hline Manual Wheelchair & $5.77 *$ & 5.95 & 5.50 & 5.14 \\
\hline$(\mathrm{n}=284)$ & $(.07)$ & $(.08)$ & $(.08)$ & $(.11)$ \\
\hline
\end{tabular}

Note. All values are adjusted for years post injury.

$*_{\text {values are significantly different }(p=.001)}$ 
Figure 1. Path models showing path estimates for Theory of Planned Behaviour variables as predictors of moderateheavy LTPA (MH-LTPA) among ambulators (bold text) and manual wheelchair users (unbolded text).

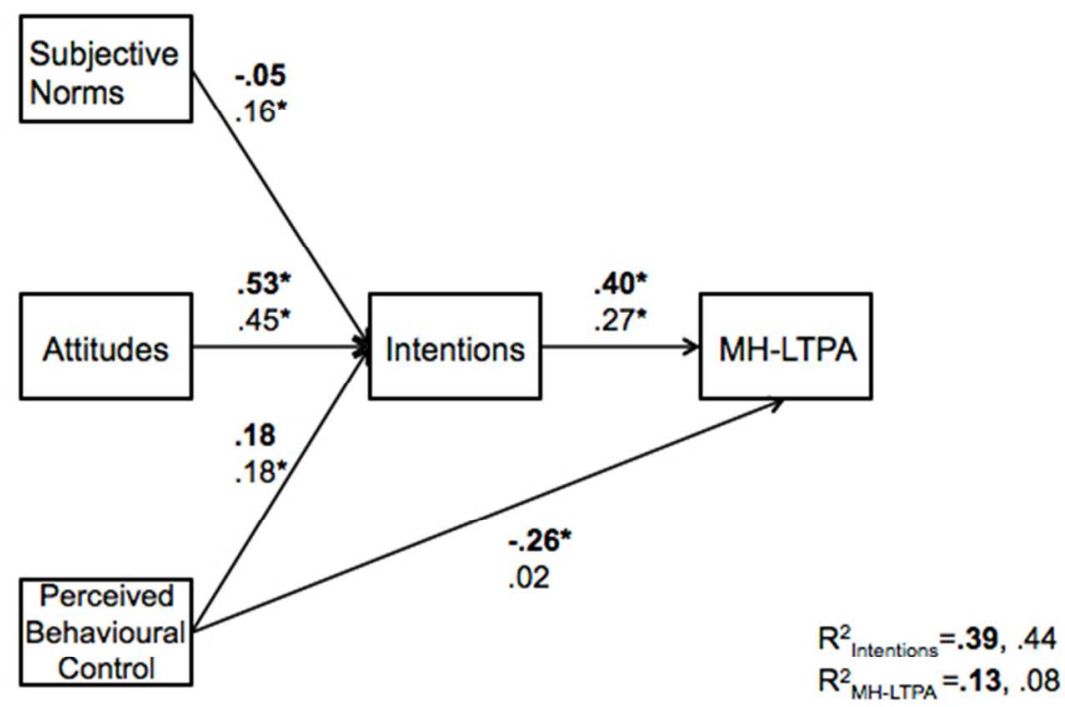

$226 \times 166 \mathrm{~mm}(72 \times 72 \mathrm{DPI})$ 